\title{
A Study of the Behavior of Alkyl Side Chains Phenols and Arenes in Polar and Nonpolar GC Stationary Phases
}

\author{
Pavel Straka $^{*}$, Petr Buryan ${ }^{2}$ \\ ${ }^{1}$ Institute of Rock Structure and Mechanics, Academy of Sciences of the Czech Republic, Prague, Czech Republic \\ ${ }^{2}$ Institute of Chemical Technology, Prague, Czech Republic \\ E-mail: straka@irsm.cas.cz \\ Received July 17, 2010; revised January 10, 2010; accepted January 20, 2011
}

\begin{abstract}
Gas chromatographic measurements of the relative retention times of alkyl-substituted arenes and phenols on capillary columns at temperatures of $125^{\circ} \mathrm{C}-140^{\circ} \mathrm{C}$ have shown that logarithms of retention times increase bi-linearly with the number of carbon atoms in the molecule. It was found that in a high density stationary phase, the longer alkyl side chains of compounds in question are subject to cyclization as a result of the resistance force of this phase affecting molecules during their thermal and diffusion motion. Consequently, common conventional aromatic-aliphatic molecules become new molecules with quasi-alicyclic rings. In comparison with the conventionally conceived molecules, the resulting aromatic-quasi-alicyclic molecules are characterized by rather different, possibly even completely different non-covalent interactions between the molecules, which then affect the retention characteristics. Moreover, cyclization facilitates the mixing of n-alkyl arenes or n-alkyl phenols with high-molecular stationary phases, because the thermodynamic condition for mixing is better fulfilled.
\end{abstract}

Keywords: Alkyl Phenols, Alkyl Benzenes, Retention Times, Molecular Mechanics, Van der Waals Forces

\section{Introduction}

The following considerations presented were based on gas chromatographic measurements on capillary columns (50 m, an internal diameter of $0.25 \mathrm{~mm}$ ) with stationary phases Apiezon K (nonpolar) and tri (2,4-xylenyl) phosphate-phosphoric acid (95:5) (polar) [1-6]. The measurements of the relative retention times $\left(R_{t, \text { rel }}\right)$ of n-alkyl phenols and n-alkyl benzenes $\mathrm{C}_{7}-\mathrm{C}_{12}$ on these capillary columns with both polar and nonpolar stationary phases at temperatures of $125^{\circ} \mathrm{C}-140^{\circ} \mathrm{C}$ showed that the logarithms of these retention times increase bi-linearly with the number of carbon atoms in a molecule $(z)$ (Figure 1) [1]. Two linear areas in the consecutive intervals $\mathrm{C}_{7}-\mathrm{C}_{9}$ and $\mathrm{C}_{9}-\mathrm{C}_{12}$, with the slopes of each line being different, were proven in the relation $\log R_{t, \text { rel }}=a z+b \quad$ (where $a$ and $b$ are constants), although only one line had been anticipated to be found. The complete dependence was thus of a bi-linear character. This dependence was also found under the mentioned conditions in the case of n-alkyl phenol methylethers [1].

In classic considerations on the dependence of retention times on the number of carbons in different ho- mo- logous series of gas chromatographically separated substances, purely linear dependence without any divergence is always considered, be it for isotherm or nonisotherm separations [2-6].

However, the divergence detected in the dependence $\log R_{t, \text { rel }}=a z+b$ suggests that the behavior of molecules of the compounds in question during separations in stationary phases is more complicated than has been assumed by the classic considerations. The relation $\log R_{t, \text { rel }}=a z+b$ should be expected to be purely linear as a result of the growing number of carbon atoms in the molecule [2-6] and the corresponding increase of $R_{t, \text { rel }}$ or more precisely $\log R_{t, \text { rel }}$ with boiling points $\left(T_{b}\right)$ of the given homologs $\left(\log R_{t, \text { rel }}=a+b T_{b}\right)$. The mentioned purely linear relation has frequently been applied in the identification of unknown substances using data acquired through gas chromatographic separations, but the validity of this usage is questionable.

In the study [1], the relative retention times were expressed as a logarithm of the ratio of the retention time of the given n-alkyl phenol substituted in the ortho, meta and para positions and phenol, and in the case of n-alkyl benzenes as a logarithm of the ratio of the retention time 
of n-alkyl benzene and benzene. The mentioned bi-linearity in the increase of mentioned retention characteristics was always observed at $\mathrm{C}_{9}$.

In a preliminary work [7], the following possibilities were considered for explanation of this phenomenon. Firstly, cyclization of alkyl side chains was taken into account. In a high density stationary phase, the longer alkyl side chains of n-alkyl phenols and n-alkyl benzenes are subject to cyclization as a result of the resistance force of this phase affecting the molecules of the compounds during their thermal and diffusion motion. Consequently, common conventional aromatic-aliphatic molecules become new molecules with quasi-alicyclic parts. In comparison with the conventionally conceived molecules, the resulting aromatic-quasi-alicyclic molecules are likely to be characterized by rather different, possibly even completely different non-covalent interactions between the molecules, chiefly van der Waals interactions, which then affect the retention characteristics.

Further, association of the molecules was considered. The molecules of the compounds in question are of an aromatic-aliphatic character. Such molecules tend, in a dense environment (e.g. in organic gels), to form molecular aggregates, as was discovered during the research

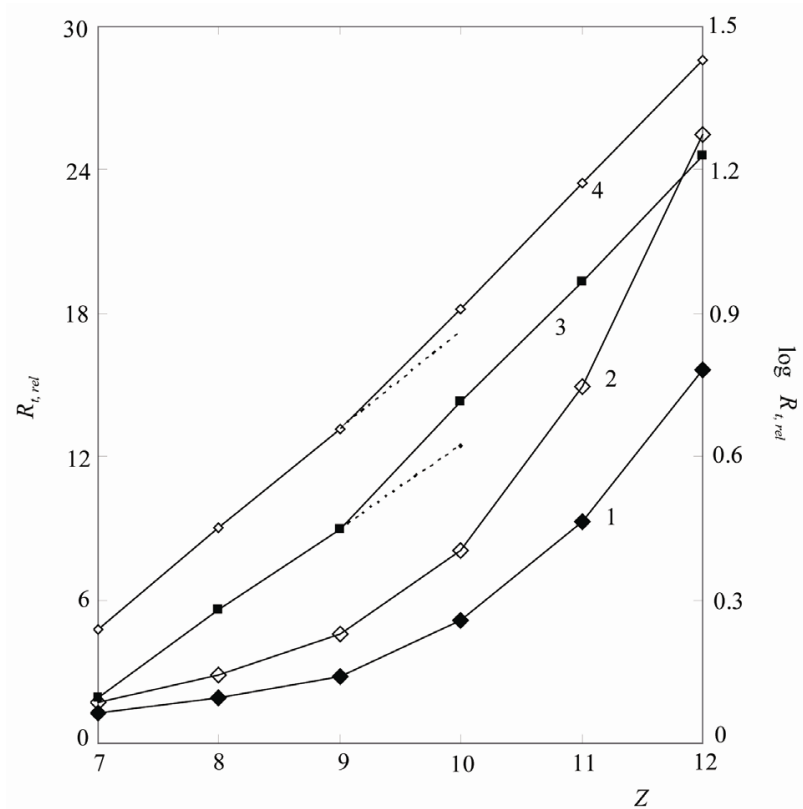

Figure 1. The dependence of the relative retention time ( $R_{t, \text { rel }}$ ) (lines 1 and 2) and bi-linear dependence of $\log R_{t, \text { rel }}$ (lines 3 and 4) on the number of carbons in the molecule ( $z$ ) for the stationary phase of Apiezon $\mathrm{K}$ at a temperature of $130^{\circ} \mathrm{C}$ in the case of $n$-alkyl phenols. (Column oven temperature $130^{\circ} \mathrm{C}$, liquid injector $300^{\circ} \mathrm{C}$, carrier gas: nitrogen, FID.) Full points-ortho n-alkyl phenols; empty points-para n-alkyl phenols. Similar dependences were found also in the case of n-alkyl benzenes and n-alkyl phenol methylethers. Based on [1], adjusted. on the formation of coal structures [8]. A similar phenomenon may occur in the environment of a dense stationary phase. The molecules in question may associate, which would lead to a change in retention characteristics. The association could also increase with the growing length of the side alkyl chain and might strongly manifest itself in the case of molecules containing more than nine carbons. Therefore, a close association was investigated both in the case of n-alkyl phenols and n-alkyl benzenes for the system of two molecules. This was done by calculating the energies of the van der Waals interacttions ( $E_{v d \text { Waals }}$ ) using the molecular mechanics modeling. Two molecules were conformed until the state of the energy minima was reached and the calculated energies were compared with the energies of the van der Waals interactions in two non-associated (isolated) molecules. It was found that intensive nonbonding interactions occur in the association of the two molecules, however, no dependence of the $E_{v d \text { waals }}$ values on the length of the nalkyl chain was registered. Thus, this way of influencing of the retention characteristics is unlikely.

Finally, non-covalent interactions with a stationary phase were taken into account. With the increasing number of carbons in the molecule of n-alkyl phenols and nalkyl benzenes, the intermolecular interactions between the compounds in question and the stationary phase might change non-linearly, but these interactions must manifest themselves differently in polar and nonpolar phases. Nevertheless, this was not observed. The character of the dependences was the same, bi-linear, measured in the case of alkyl benzenes for both the polar and nonpolar phases. The same was found with alkyl phenols. So, this

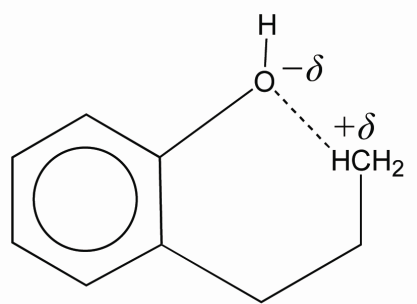

a

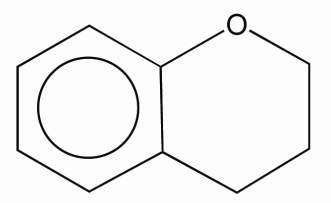

c

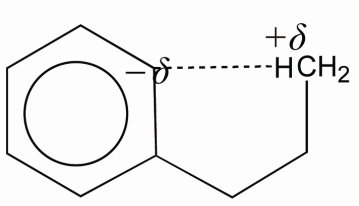

b

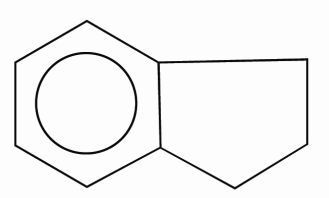

d
Figure 2. Concepts of the cyclized forms in the case of ortho n-propyl phenol (a) and n-propyl benzene (b). The cyclization is realized on the terminal methyl group $\left(-\mathrm{CH}_{3}\right.$ cyclization). Concepts (c) and (d) are depicted as the models for energies calculations. 
interpretation of the observed retention phenomena was abandoned. Therefore, it was the cyclization alkyl chains of the considered compounds that was preferred. The preference for the cyclization arises also from the fact that alicyclic-aromatic ethers with five- and six-membered alicyclic rings with oxygen and an interconnected aromatic ring (Figure 2), which are thermodynamically stable compounds, are formed.

The mentioned phenomena can be evaluated and compared using methods of computational chemistry. In order to assess cyclization, association and different interactions, the energies of the covalent bonds and non-covalent interactions, mainly van der Waals, can be computed. For the purpose of this assessment, molecular conformations which are realistic and energetically advantageous or possible and are in correlation with the ascertained chromatographic data can also be estimated. On the basis of experience with the evaluation of aromatic, aromatic-aliphatic, aromatic-alicyclic and phenolic structures in terms of energy using the methods of molecular mechanics [79], two methods of molecular mechanics were selected for the calculations (see below). Recently, the molecular mechanics method was successfully used to study cyclization reactions [10].

The aim of the presented work is to explain the bi- linearity in the logarithmic dependence of the relative retention time on the number of carbons in the molecule in the case of n-alkyl phenols and n-alkyl benzenes by molecular mechanics modeling and to clarify the behavior of these compounds in the environment of a stationary phase of a capillary column. The potential energies of the bonds and interactions have been considered for the cal- culations.

\section{Calculations}

In our considerations, the retention data obtained on a nonpolar stationary phase of Apiezon $\mathrm{K}$ and a polar stationary phase of trixylenylphosphate-phosphoric acid (95: 5) at a temperature of $130^{\circ} \mathrm{C}$ according to [1] were taken into account.

For the calculations, the molecular mechanics methods were selected [11-13] and two force fields, MM+ and AMBER, were used. The reason is that these methods use analytical and relatively simple potential energy functions for describing the interactions between a set of atoms; further, they are empirical and accurate and very suitable for small organic molecules. What is important is that the atom types, not atoms, are the fundamental basis for calculating the interactions. In these methods, the interaction potential describes both bonding and non-bonding interactions. In the potential, the following energetic terms were calculated: bond stretching ( $\left.E_{\text {bond }}\right)$, which is associated with the deformation of a bond from its standard equilibrium length;

- $\quad$ bond angle bending ( $E_{\text {angle }}$ ), which is associated with the deformation of an angle from its normal value; stretch-bend ( $E_{\text {stretch-bend }}$ ) - the bond-stretching and angle-bending cross term, which includes coupling between the bond stretching and angle bending;

dihedrals ( $\left.E_{\text {dihedral }}\right)$-the torsional energy, which is associated with the tendency of dihedral angles to have a certain $n$-fold symmetry and to have minimum energy; van der Waals ( $E_{v d \text { waals }}$ ), which describes the repulsive forces keeping two non-bonded atoms apart at close range and attractive forces drawing them together at long range;

- $\quad$ electrostatic ( $\left.E_{\text {elst }}\right)$, which describes the nonbonded electrostatic interactions, particularly dipole-dipole interactions.

These energetic terms were calculated both by the $\mathrm{MM}+$ and AMBER methods, with the exception of $E_{\text {stretch-bend }}$, which was calculated only by means of the MM+ method.

The mentioned potential energies of the covalent bonds and non-covalent interactions were calculated for common (conventional) n-alkyl phenols and n-alkyl benzenes and also for the models of the cyclized forms of these compounds. The concepts of the cyclized forms were formulated on the basis of the study of the distribution of electron densities (atomic charges in a molecule) in common and cyclized molecules. As expected, in n-alkyl phenol molecules, a high electron density was found on the oxygen of the hydroxyl group and a very low electron density on hydrogens of the terminal methyl group. The closing of the alicyclic ring was thus easily implemented by the hydrogen bridge as shown in Figure 2(a). The concept of the cyclized form of alkyl benzenes was more complicated. The electron density on the methyl carbon was discovered to be considerably higher than on the other carbons and, especially, on hydrogen atoms of the methyl group in an alkyl chain. The closing of the ali- cyclic ring was thus implemented by an interaction of methyl hydrogen with the ascribed charge $+\delta$ and the benzene ring with the ascribed charge $-\delta$ (Figure 2(b)). The basic concepts of cyclized forms and models of these forms, for the sake of calculations demonstrated on npropyl phenol and n-propyl benzene, are shown in Figures 2(c) and 2(d), namely for the case of alicyclic ortho n-propyl phenol and alicyclic n-propyl benzene. In the latter case, n-propylbenzene is cyclized to the ortho position with respect to the propyl. The cyclization here is implemented on the terminal methyl group $\left(-\mathrm{CH}_{3}\right.$ cyclization).

Besides the $-\mathrm{CH}_{3}$ case, cyclization was also considered 
Table 1. Reduction of the maximum molecular size $\left(D_{\max }\right)$ during cyclization of the side alkyl chain. Comparison of $D_{\max }$ values for common and cyclized forms of n-alkyl phenols.

\begin{tabular}{cccc}
\hline Molecule & \multicolumn{3}{c}{$D_{\max }(\mathrm{nm})$} \\
& ortho & $\begin{array}{c}\text { Position of substituent: } \\
\text { meta }\end{array}$ & para \\
Common: & & & 0.59 \\
Methyl phenol & 0.56 & 0.72 & 0.80 \\
Ethyl phenol & 0.72 & 0.83 & 0.91 \\
n-Propyl phenol & 0.82 & 0.95 & 1.04 \\
n-Butyl phenol & 0.93 & 1.08 & 1.15 \\
n-Pentyl phenol & 1.06 & 1.21 & 1.28 \\
n-Hexyl phenol & 1.19 & & \\
Cyclized on -CH $:$ & & & 0.47 \\
Methyl phenol & & 0.49 & 0.48 \\
Ethyl phenol & 0.56 & 0.55 & 0.57 \\
Propyl phenol & 0.65 & 0.61 & 0.54 \\
Butyl phenol & 0.72 & 0.66 & 0.61 \\
Pentyl phenol & 0.72 & 0.70 & 0.73 \\
Hexyl phenol & 0.80 & 0.71 & \\
\hline
\end{tabular}

and calculated for the $-\mathrm{CH}_{2}$ - group neighboring $\mathrm{CH}_{3}$ - (i.e. in the $\alpha$ position with respect to $\mathrm{CH}_{3}^{-},-\mathrm{CH}_{2}-\alpha$ cyclization) and for the $-\mathrm{CH}_{2}$ - group in the $\beta$ position with respect to the $\mathrm{CH}_{3}$ - group (- $\mathrm{CH}_{2}-\beta$ cyclization). These cyclizations were considered for molecules from methylup to hexyl phenol and from methyl- up to hexyl benzene. With n-alkyl phenols and n-alkyl benzenes, these cyclizations were considered and calculated for the ortho, meta and para positions. The calculated energies of covalent bonds and non-covalent interactions for common and model cyclic forms were compared, but no significant changes in energetic terms were found. Moreover, in the case of the $-\mathrm{CH}_{2}-\alpha$ and $-\mathrm{CH}_{2}-\beta$ cyclizations, the calculated $E_{v d \text { waals }}$ values were similar to common n-alkyl phenols and n-alkyl benzenes and no relevant dependences on $z$ were found.

The HyperChem program also makes it possible to measure the distance and the maximum distance between atoms of defined molecule (maximum size, $D_{\max }$ ). This possibility was utilized for the measurement and comparison of the maximum sizes of the common and cyclized molecules of the examined compounds. The Atomic Charges part of the program was used for the study of the above-mentioned distribution of the electron densities in the molecules of the observed compounds.

\section{Results and Discussion}

The side-chain cyclization was based on the concept that in a high-density stationary phase, the longer side alkyl chains of n-alkyl phenols and n-alkyl benzenes are subject to deformation as a result of the resistance of this phase affecting the molecules of these compounds in motion. Conventional aromatic-aliphatic molecules are thus transformed into aromatic-quasi-alicyclic molecules. Cycliza- tion is then accompanied by a decrease in the effective size of molecules, which is significant for $\mathrm{C}_{9}$ and larger molecules. Aromatic-quasi-alicyclic molecules of a smaller size are more easily mixed with the dense stationary phase, and the formed system is, in comparison with a system with common aromatic-aliphatic molecules, more homogenous and thus thermodynamically more stable. The reduction of the maximum size $\left(D_{\max }\right)$ of molecules during the cyclization of the side chain is shown in Table 1. The change in size of the molecules moving through a chromatographic column is then accompanied by changes

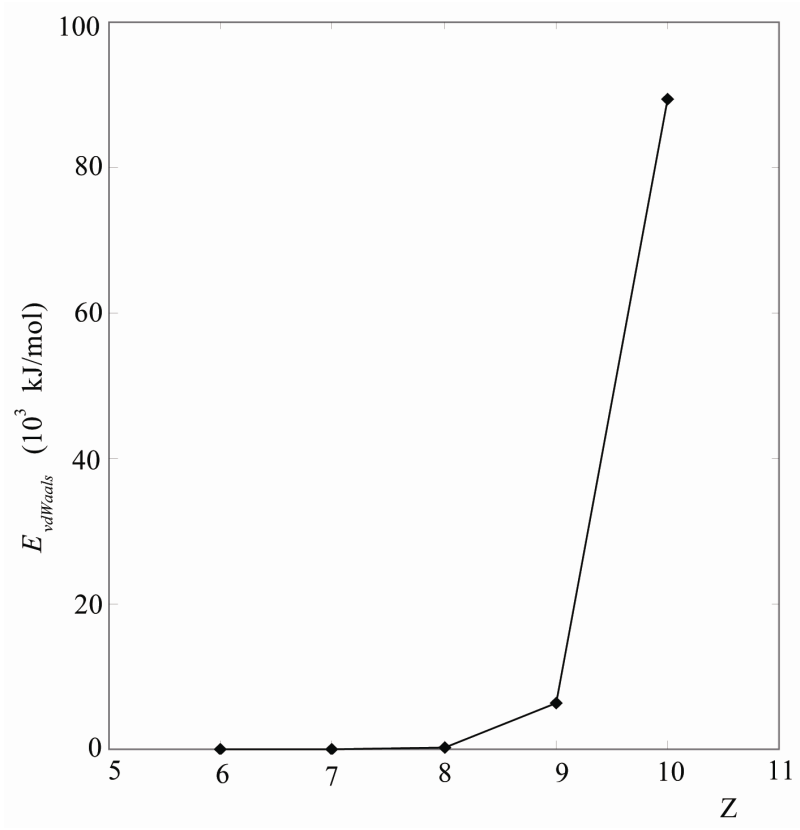

Figure 3. The dependence of the van der Waals energies (and consequently forces) in effect on the number of carbons in the cyclized molecules of para n-alkyl phenols (the AMBER method, $-\mathrm{CH}_{3}$ cyclization). 
Table 2. Potential energies of covalent bonds and non-covalent interactions in meta n-alkyl phenols (common and cyclized on $\mathrm{CH}_{3}$-). Calculated by the MM+ program. For symbols see text.

\begin{tabular}{|c|c|c|c|c|c|c|c|}
\hline n-alkyl phenols & $E_{\text {bond }}$ & $E_{\text {angle }}$ & $E_{\text {stretch-bend }}(\mathrm{kJ} / \mathrm{mol})$ & $E_{\text {dihedral }}$ & $E_{\text {vdWaals }}$ & $E_{\text {elst }}$ & $D_{\max }(\mathrm{nm})$ \\
\hline Phenol & 4.57 & 9.43 & -0.44 & -23.32 & 12.11 & 0 & 0.56 \\
\hline \multicolumn{8}{|l|}{ Common: } \\
\hline Methyl phenol & 6.90 & 9.68 & -0.59 & -26.33 & 14.57 & 0.11 & 0.59 \\
\hline Ethyl phenol & 8.80 & 9.68 & -0.58 & -26.92 & 39.44 & 0.11 & 0.72 \\
\hline n-Propyl phenol & 10.70 & 9.68 & -0.58 & -26.92 & 42.49 & 0.11 & 0.83 \\
\hline n-Butyl phenol & 12.60 & 9.68 & -0.57 & -26.92 & 45.48 & 0.11 & 0.95 \\
\hline n-Pentyl phenol & 14.50 & 9.68 & -0.57 & -26.92 & 48.66 & 0.11 & 1.08 \\
\hline n-Hexyl phenol & 16.40 & 9.69 & -0.57 & -26.92 & 51.84 & 0.11 & 1.21 \\
\hline \multicolumn{8}{|l|}{ Cyclized on $\mathrm{CH}_{3}$ : } \\
\hline Methyl phenol & 10.26 & 38.69 & -0.96 & 389.88 & 32.45 & 0.00 & 0.49 \\
\hline Ethyl phenol & 13.81 & 36.63 & -3.06 & 369.97 & 95.81 & 0.49 & 0.55 \\
\hline Propyl phenol & 29.75 & 64.02 & 3.70 & 243.10 & 385.13 & 0.16 & 0.61 \\
\hline Butyl phenol & 31.13 & 59.18 & 1.73 & -1.34 & 3173.3 & 0.05 & 0.66 \\
\hline Pentyl phenol & 19.09 & 29.00 & 0.58 & -13.30 & 2941.5 & 0.04 & 0.69 \\
\hline Hexyl phenol & 16.64 & 4.66 & -0.04 & -10.80 & 8006.8 & 0.05 & 0.71 \\
\hline
\end{tabular}

Table 3. Potential energies of covalent bonds and non-covalent interactions in n-alkyl benzenes cyclized into the position meta with respect to the substituent (common and cyclized on $\mathrm{CH}_{3}-$ ). Calculated by the $\mathrm{MM}+$ program. For symbols see text.

\begin{tabular}{|c|c|c|c|c|c|c|c|}
\hline n-alkyl benzenes & $E_{\text {bond }}$ & $E_{\text {angle }}$ & $E_{\text {stretch-bend }}(\mathrm{kJ} / \mathrm{mol})$ & $E_{\text {dihedral }}$ & $E_{\text {vdWaals }}$ & $E_{\text {elst }}$ & $D_{\max }(\mathrm{nm})$ \\
\hline Benzene & 4.57 & 9.43 & -0.44 & -23.32 & 12.11 & 0 & - \\
\hline \multicolumn{8}{|l|}{ Common: } \\
\hline Methyl benzene & 7.06 & 0.25 & -0.14 & -26.33 & 14.85 & 0 & 0.59 \\
\hline Ethyl benzene & 8.96 & 0.25 & -0.13 & -26.92 & 39.73 & 0 & 0.72 \\
\hline n-Propyl benzene & 10.86 & 0.25 & -0.13 & -26.92 & 42.78 & 0 & 0.82 \\
\hline n-Butyl benzene & 12.76 & 0.25 & -0.13 & -26.92 & 45.77 & 0 & 0.95 \\
\hline n-Pentyl benzene & 14.66 & 0.25 & -0.13 & -26.92 & 48.96 & 0 & 1.06 \\
\hline n-Hexyl benzene & 16.56 & 0.25 & -0.13 & -26.92 & 52.14 & 0 & 1.19 \\
\hline \multicolumn{8}{|l|}{ Cyclized on $\mathrm{CH}_{3}$ : } \\
\hline Methyl benzene & 7.83 & 123.13 & -3.58 & 194.74 & 41.50 & 0 & 0.47 \\
\hline Ethyl benzene & 10.27 & 29.47 & -2.27 & 292.85 & 34.23 & 0.56 & 0.51 \\
\hline Propyl benzene & 12.86 & 21.61 & -1.06 & 305.63 & 54.08 & 0.24 & 0.57 \\
\hline Butyl benzene & 27.34 & 50.05 & 2.48 & 185.38 & 257.72 & 0.16 & 0.62 \\
\hline Pentyl benzene & 30.44 & 49.67 & 0.98 & -2.50 & 3102.9 & 0.13 & 0.66 \\
\hline Hexyl benzene & 17.22 & 5.30 & -0.12 & -0.57 & - & 0.13 & 0.69 \\
\hline
\end{tabular}

in the intermolecular interactions and subsequently by a change in the relative retention time.

The calculation results for the energies of the covalent bonds and non-covalent interactions are demonstrated for meta n-alkyl phenols (common and cyclized on $\mathrm{CH}_{3}^{-}$) and n-alkyl benzenes both common and cyclized into the meta position with respect to the substituent (again cyclization through $\mathrm{CH}_{3}-$ ), are summarized in Tables 2 and 3.

From Tables 2 and $\mathbf{3}$ it is evident that cyclization does not cause significant changes in covalent bonds, only small changes in electrostatic interactions and some expected changes in the $E_{\text {angle }}$ term was registred. However, substantial changes took place in the van der Waals interactions between the non-bonded atoms inside the molecules. Typical dependence of the van der Waals forces on the number of carbons $(z)$, shown in the example of para n-alkyl phenols, is pictured in Figure 3. This is of the similar character as the detected dependence of the logarithm of the relative retention time on $Z$ (Figure 1, lines 3 and 4). This finding is in agreement with the fact that the same dependences were detected both in the cases of the polar and nonpolar phases and also in the cases of alkyl phenols and alkyl benzenes, because the retention data and their changes are in the given case related to intermolecular forces rather than to the structure of the compounds being considered. The similar results have been obtained in the case of ortho phenols cyclized on the $-\mathrm{CH}_{3}$ group and also in the case of the n-alkyl benzenes cyclized on the $-\mathrm{CH}_{3}$ group into ortho and para positions with respect to the substituent. Therefore, attention was focused on systematic calculations of the energies of the van der Waals interactions. The numerical values of these energies showed the strength of the van der Waals forces; the results are summarized in Tables 4 and 5. From the data in these tables, it is clear that the bi-linearity in these interactions occurs at $z=9$ (to be more specific when the phenol or benzene are substituted by n-propyl) during cyclization. However, this result was ascertained only for n-alkyl phenols and n-alkyl benzenes cyclized on the terminal methyl group. In the case of the $-\mathrm{CH}_{2}-\alpha$ and $-\mathrm{CH}_{2}-\beta$ 
Table 4. Energies of van der Waals interactions ( $E_{\text {vdwals }}, \mathrm{kJ} / \mathrm{mol}$ ) in the molecules of $\mathrm{n}$-alkyl phenols and n-alkyl benzenes. Calculated by the MM+ program. Positions “ortho", "meta”, "para” at n-alkyl benzenes mean cyclization into the positions with respect to the substituent.

\begin{tabular}{|c|c|c|c|c|c|c|c|}
\hline n-alkyl phenols & ortho & meta & para & n-alkyl benzenes & "ortho" & "meta" & "para" \\
\hline Common: & & & & Common: & & & \\
\hline Methyl phenol & 17.12 & 14.57 & 14.60 & Methyl benzene & 14.85 & 14.85 & 14.85 \\
\hline Ethyl phenol & 41.25 & 39.44 & 39.47 & Ethyl benzene & 39.73 & 39.73 & 39.73 \\
\hline n-Propyl phenol & 44.24 & 42.49 & 42.51 & n-Propyl benzene & 42.78 & 42.78 & 42.78 \\
\hline n-Butyl phenol & 47.23 & 45.48 & 45.51 & n-Butyl benzene & 45.77 & 45.77 & 45.77 \\
\hline n-Pentyl phenol & 50.40 & 48.66 & 48.69 & n-Pentyl benzene & 48.96 & 48.96 & 48.96 \\
\hline n-Hexyl phenol & 53.58 & 51.84 & 51.87 & n-Hexyl benzene & 52.14 & 52.14 & 52.14 \\
\hline Cyclized on $\mathrm{CH}_{3}$ : & & & & Cyclized on $\mathrm{CH}_{3}$ : & & & \\
\hline Methyl phenol & 11.39 & 32.45 & 44.96 & Methyl benzene & 10.40 & 41.50 & 23.99 \\
\hline Ethyl phenol & 12.09 & 95.81 & 109.4 & Ethyl benzene & 11.23 & 34.23 & 46.87 \\
\hline Propyl phenol & 27.61 & 385.1 & 411.3 & Propyl benzene & 14.25 & 54.08 & 67.42 \\
\hline Butyl phenol & 49.25 & 3173 & 1037 & Butyl benzene & 27.64 & 257.7 & 339.3 \\
\hline Pentyl phenol & 210.20 & 2942 & 1132 & Pentyl benzene & 64.51 & 3103 & 832.2 \\
\hline Hexyl phenol & - & 8007 & - & Hexyl benzene & 476.8 & - & 905.6 \\
\hline
\end{tabular}

Table 5. Energies of van der Waals interactions $\left(E_{v d W a a l s}, \mathrm{~kJ} / \mathrm{mol}\right)$ in the molecules of $\mathrm{n}$-alkyl phenols and n-alkyl benzenes. Calculated by the AMBER program. Positions “ortho", “meta”, "para” at n-alkyl benzenes mean cyclization into the positions with respect to the substituent.

\begin{tabular}{|c|c|c|c|c|c|c|c|}
\hline n-alkyl phenols & ortho & meta & para & n-alkyl benzenes & „ortho“ & „meta“ & „para“ \\
\hline Common: & & & & Common: & & & \\
\hline Methyl phenol & 17.54 & 13.53 & 13.58 & Methyl benzene & 13.90 & 13.90 & 13.90 \\
\hline Ethyl phenol & 36.17 & 35.04 & 35.09 & Ethyl benzene & 35.43 & 35.43 & 35.43 \\
\hline n-Propyl phenol & 36.54 & 35.48 & 35.53 & n-Propyl benzene & 35.87 & 35.87 & 35.87 \\
\hline n-Butyl phenol & 37.13 & 36.07 & 36.13 & n-Butyl benzene & 36.48 & 36.48 & 36.48 \\
\hline n-Pentyl phenol & 37.90 & 36.86 & 36.91 & n-Pentyl benzene & 37.26 & 37.26 & 37.26 \\
\hline n-Hexyl phenol & 38.71 & 37.67 & 37.72 & n-Hexyl benzene & 38.07 & 38.07 & 38.07 \\
\hline Cyclized on $\mathrm{CH}_{3}$ : & & & & Cyclized on $\mathrm{CH}_{3}$ : & & & \\
\hline Methyl phenol & 14.93 & 43.83 & 65.28 & Methyl benzene & 12.92 & 55.41 & 24.34 \\
\hline Ethyl phenol & 11.05 & 141.6 & 175.1 & Ethyl benzene & 14.35 & 40.43 & 53.46 \\
\hline Propyl phenol & 19.08 & 2976 & 6247 & Propyl benzene & 11.52 & 61.62 & 74.65 \\
\hline Butyl phenol & 38.38 & $4 * 10^{6}$ & $9 * 10^{4}$ & Butyl benzene & 16.90 & 1083 & 4183 \\
\hline Pentyl phenol & 703.1 & $4 * 10^{6}$ & - & Pentyl benzene & 61.29 & $6 * 10^{6}$ & 35913 \\
\hline Hexyl phenol & - & $4 * 10^{10}$ & - & Hexyl benzene & - & - & - \\
\hline
\end{tabular}

cyclizations, the detected $E_{v d \text { waals }}$ values were similar to common n-alkyl phenols and n-alkyl benzenes and no relevant dependences on $z$ were found, as stated above.

An increase in the van der Waals interactions inside the cyclized molecules (i.e. intramolecularly) must also be reflected in an increase of the forces between molecules (i.e. intermolecularly). A more intense effect of the attraction forces between molecules should then manifest itself through a corresponding increase of the boiling temperatures of the $\mathrm{C}_{9}$-compounds and be higher in both types of molecules in question. The increase of the intermolecular forces caused by cyclization was confirmed by a comparison of the boiling points of normal $\left(-42.1^{\circ} \mathrm{C}\right.$ $\left.-125.5^{\circ} \mathrm{C}\right)$ and alicyclic $\left(-33.5^{\circ} \mathrm{C}-150^{\circ} \mathrm{C}\right)$ hydrocarbons $\mathrm{C}_{3}-\mathrm{C}_{8}$. The results are shown in Table 6. The values of the boiling points were taken from the compendium [14] and verified against the compendium [15]. From the values shown in Table 6, it is evident that the boiling points of alicyclic hydrocarbons increase with the number of carbons $z$ in the molecule similarly to van der
Waals forces.

If a change in the relative retention time as a result of cyclization is caused by a change in the size of the molecule moving in a chromatographic column and a change in both intramolecular and intermolecular van der Waals forces, then the related cyclization of the alkyl chain could really be, in the case of n-alkyl phenols, accompanied by the formation of a hydrogen bridge between the oxygen in the phenolic group - $\mathrm{OH}$ and a hydrogen of the terminal group $-\mathrm{CH}_{3}$ of the alkyl; in other words, in the case of n-alkyl phenols, the tendency to form hydrogen bridges resulting in a heterocyclic ring with six or more members being formed including also one $\mathrm{C}-\mathrm{C}$ bond of the aromatic ring of phenol as shown in Figure 2 could actually be considered. Similarly, in the case of alkyl benzenes, a tendency to integrate could exist between the benzene ring $(-\delta)$ and a hydrogen of the terminal group $-\mathrm{CH}_{3}$ of the alkyl $(+\delta)$, resulting in the formation of a five-membered or more-membered ring, including also one $\mathrm{C}-\mathrm{C}$ bond of the aromatic ring of benzene (Figure 2). From the thermodynamical aspect, it 
Table 6. Boiling points $\left(T_{b}\right)$ of normal and alicyclic hydrocarbons $C_{3}-C_{8}$ and energies of intramolecular van der Waals interactions.

\begin{tabular}{cccc}
\hline Alkane & $T_{b}\left({ }^{\circ} \mathrm{C}\right)$ & $\begin{array}{c}E_{\text {vdwals }}(\mathrm{MM}+) \\
(\mathrm{kJ} / \mathrm{mol})\end{array}$ & $\begin{array}{c}E_{\text {vdwaals }} \\
(\mathrm{kJ} / \mathrm{mol})\end{array}$ \\
\hline Propane & -42.1 & 8.47 & 1.84 \\
n-Butane & -0.5 & 11.87 & 2.80 \\
n-Pentane & 36.15 & 15.13 & 3.67 \\
n-Hexane & 68 & 18.36 & 4.51 \\
n-Heptane & 98.34 & 21.58 & 5.36 \\
n-Octane & 125.5 & 24.79 & 6.19 \\
& & & \\
Cyclopropane & -33.5 & 0.13 & 0.07 \\
Cyclobutane & 13 & 11.27 & 1.23 \\
Cyclopentane & 49.26 & 14.77 & 2.40 \\
Cyclohexane & 81 & 22.12 & 5.34 \\
Cycloheptane & 118.48 & 204.8 & 721.5 \\
Cyclooctane & 150 & 501.1 & 7840 \\
\hline
\end{tabular}

is the affinity of these low-molecular compounds to the stationary high-molecular phase that is important when they are being mixed with this phase. The degree of affinity is the change in the Gibbs free energy of mixing when the molecules of alkyl phenol or alkyl benzene are blended with high-molecular chains or molecules of the stationary phase $\left(\Delta G_{m i x}\right)$ at constant temperature and pressure:

$$
\Delta G_{\text {mix }}=\Delta H_{\text {mix }}-T \Delta S_{\text {mix }}<0
$$

where $\Delta H_{\text {mix }}$ is the enthalpy of mixing, $\Delta S_{\text {mix }}$ the entropy of mixing and $T$ the temperature of the separation (K). The more negative the $\Delta G_{\text {mix }}$ is, the better the mixing of the compounds will be (for the stationary phase). Since the entropy of the system always increases when the components are mixed, and the entropic term of the Equation (1) is thus always negative $\left(-T \Delta S_{\text {mix }}<0\right)$, the mixing/solubility depends mainly on the value of $\Delta H_{\text {mix }}$. The thermodynamic condition of the solubility of a low-molecular element in the stationary phase, or the mixing of the two substances is then:

$$
\Delta H_{\text {mix }}<T \Delta S_{\text {mix }}
$$

The blending will thus be the best in the case $\Delta H_{\text {mix }}$ $=0$, when also the solubility of one component in the other will be maximal as well. However, this is an ideal case. The parameters of the solubility $\delta$ were introduced for practical purposes, numerically characterizing the solubility of low-molecular and high-molecular substances [16]. A low-molecular substance with a solubility parameter identical to the solubility parameter of the high-molecular substance will achieve maximal dissolution during the mixing, because $\Delta H_{\text {mix }}=0$ in this case. Since cyclization increases $\delta$ in the case of hydrocarbons, e.g. in the case of hexan/cyclohexan from 14.9 (hexan) to 16.8 (cyklohexan) [17], the mixing is improved, because this parameter for the high-molecular stationary phases [18] can be approximately 16 - 18. Cyclization thus faci- litates the mixing of alkyl phenols or alkyl benzenes with high-molecular stationary phases, because the thermodynamic condition for mixing is better fulfilled.

On the whole, the data obtained can both serve an analytical methodology for the analysis of aromatics and phenolics, which is still being discussed [19], and provide deeper insight into the problem of the van der Waals forces/non-covalent interactions, which is also a topic of interest [20].

\section{Conclusions}

The side alkyl chains of n-alkylphenols become cyclized in both the polar and nonpolar stationary phases of capillary columns, with a possible formation of hydrogen bridges between oxygen of the phenolic $\mathrm{OH}$ group and hydrogen of the methyl group of the side alkyl chain. In the case of n-alkyl benzenes, cyclization is made possible because of the interaction between benzene ring $(-\delta)$ and hydrogen of the terminal methyl group $(+\delta)$ of the alkyl chain. In the case of the formed aromatic-quasialicyclic molecules, the effect of the van der Waals forces thus increases not only intramolecularly but also intermolecularly. In the case of n-alkyl phenols and nalkyl benzenes this effect is strong with the molecules having the number of carbons higher than nine. This results in bi-linearity in the retention characteristics of these compounds, observed in the dependence of the logarithm of the relative retention time on the total number of carbons in the molecule.

\section{Acknowledgements}

This work was supported by the Grant Agency of the Academy of Sciences of the Czech Republic in the frame of project No. IAA300460702 and the Institute Research Plan, Identification Code AVOZ30460519.

\section{References}

[1] P. Buryan and J. Macák, "Partial Explanation of the Anomaly in the Relationship between the Logarithm of Retention and the Carbon Number of Monohydric Phenols," Journal of Chromatography A, Vol. 237, No. 3, 1982, pp. 381-388. doi:10.1016/S0021-9673(00)97624-6

[2] H. Purnell, “Gas Chromatography,” John Wiley and Sons Inc., New York, 1962.

[3] E. Leibnitz and H. G. Struppe, "Handbuch der GasChromatographie,” AVG \& Portik K.-G., Lepzig, 1966.

[4] G. Guiochon, "Retention Indices in Programmed Temperature Gas Chromatography,” Analytical Chemistry, Vol. 36, No. 3, 1964, pp. 661-663.

doi:10.1021/ac60209a034

[5] W. E. Hartus and H. W. Habgood, "Programmed Tem- 
perature Gas Chromatography,” John Wiley and Sons Inc., New York, 1966.

[6] C. Simpson, "Gas Chromatography,” Kogan Page, London, 1970.

[7] P. Straka, P. Buryan and J. Nahunkova, "Possibilities of Cyclization of Side Alkyl Chains of n- Alkyl Phenols and n- Alkyl Benzenes in the Environment of a Stationary Phase," Acta Geodynamica et Geomaterialia, Vol. 5, No. 1 (149), 2008, pp. 65-76.

[8] P. Straka, "Chemical structure of coal substance," Acta Montana Series AB, No. 12(132), 2003, pp. 7-47.

[9] G. A. Carlson, "Computer Studies of Coal Molecular Structure”, Proceedings 1991 International Conference on Coal Science, Newcastle upon Tyne, September 1991, pp. 24-27.

[10] A. C. T. van Duin and J. S. S. Damsté, "Computational Chemical Investigation into Isorenieratene Cyclisation,” Organic Geochemistry, Vol. 34, No. 4, 2003, pp. 515526. doi:10.1016/S0146-6380(02)00247-4

[11] A. Howard, J. McIver and J. Collins, "HyperChem Computational Chemistry," Publishing HC40-00-03-00, Hypercube Inc., Waterloo/Ontario/Canada, 1994.

[12] U. Becker and N. L. Allinger, "Molecular Mechanics," American Chemical Society, Monograph 177, Washing- ton D. C., 1982.

[13] N. L. Allinger and Y. H. Yuh, "Quantum Chemistry Program Exchange,” Indiana University, Bloomington, 1982.

[14] Collective of authors, "Spravotschnik Chimika, Osnovnyje Svojstva Neorganitcheskich I Organitcheskich Sojedinenij,” Gosudarstvennoe Nautschno-Technitscheskoe Izdatelstvo Chimitscheskoj Literatury, Moskva, 1951.

[15] M. Vecera, J. Gasparic, J. Churacek and J. Borecky, “Chemical Tables of Organic Compounds,” SNTL-Technical Literature Publishing House, Praha, 1975.

[16] J. H. Hildebrand and R. L. Scott, "Solubility of NonElectolytes,” Reinhold publishing company, New York, 1959.

[17] J. Brandrup and E. H. Immergut, "Polymer Handbook," John Wiley and Sons Inc., New York, 1975.

[18] J. Mleziva, "Polymery,” Sobotales Publishing industry, Praha, 1993, p. 467.

[19] M. Naczk and F. Shahidi, "Extraction and Analysis of Phenolics in Food,” Journal of Chromatography A, Vol. 1054, No. 1-2, 2004, pp. 95-111.

[20] P. Hobza, R. Zahradnik, K. Müller-Dethlefs, “The World of Non-Covalent Interactions: 2006," Collection Czechoslovak Chemical Communications, Vol. 71, No. 4, 2006, pp. 443-531. doi:10.1135/cccc20060443 